Article

\title{
Climate Adaptive Design Improvement Strategies of Traditional Dwellings in Southern Zhejiang for the Plum Rain Season Considering Comfort Conditions
}

\author{
Ruifeng Zheng ${ }^{1, *}$, Yufeng Zheng ${ }^{2}$, Lei Cong ${ }^{1}$, Joon-Ho Choi ${ }^{3}\left(\mathbb{D}\right.$ and Hyun Jung ${ }^{4}$ \\ 1 School of Civil Engineering and Architecture, Zhejiang University of Science and Technology, \\ Hangzhou 310023, China; 1151010001@zust.edu.cn \\ 2 Hanjia Design Group Co. Ltd., Hangzhou 310000, China; zyf@cnhanjia.com \\ 3 School of Architecture, University of Southern California, Los Angeles, CA 90089, USA; joonhoch@usc.edu \\ 4 Performance Lighting Systems, Irvine, CA 92618, USA; hyunj@performanceltg.com \\ * Correspondence: 103042@zust.edu.cn; Tel.: +86-18668151133
}

Received: 13 January 2020; Accepted: 9 March 2020; Published: 19 March 2020

check for updates

\begin{abstract}
This study investigated the adaptations of traditional dwellings to the complex regional microclimate in southern Zhejiang, China. Typical traditional dwellings in a village in the foothills and a village on the mid-slopes of Zhejiang's alpine region were selected to study traditional construction strategies for climate responsiveness and the comfort level of indoor environments during the very humid plum rain season in early summer. Fundamental analysis of the climate and architecture, a response analysis of the dwelling form, an occupants' comfort satisfaction survey, and field measurements of indoor and outdoor thermal environmental parameters were performed. The traditional dwellings and their design strategies for various regional environmental factors were explored from the perspective of (1) regional climate-adaptive strategies, (2) the thermal, airflow, lighting, and acoustic qualities of the indoor environment, and (3) the occupants' indoor environment satisfaction. The results indicated that traditional dwellings in southern Zhejiang incorporate strategies of various effectiveness in ensuring indoor comfort.
\end{abstract}

Keywords: ancient dwellings; climate responsive architecture

\section{Introduction}

\subsection{Study Background}

Traditional architectural forms are well-known for adapting to their environment [1]. To do so, buildings must balance human needs against specific geographic and climatic conditions. Through long-term trial and error, traditional dwellings have come to exhibit excellent abilities to integrate into the natural environment and adapt to unpredictable climates and challenging terrains. Recently, however, this passive architectural design strategy has become increasingly scarce [2,3]. Ancient dwellings possess "climate-adaptive" architectural forms [4] from long-term exploration and gradually accumulated architectural skills and techniques. These indoor environments are unique compared to urban residences as they apply passive technologies to directly affect the natural operation of the buildings. These passive, energy-saving technologies must be studied not only to preserve traditional architectural culture but also to inform the development of modern green and energy-efficient residential buildings.

The indoor environment of any dwelling strongly influences the physical and psychological health of the occupants. In 1985, Japanese scholar Shōzō Uchii applied "construction practice theory" to emphasize the relationship between the indoor living environment of local architecture and human 
health [5]. Rapoport analyzed the scale and material textures of local architecture and suggested that its form is affected by factors, such as natural conditions and topography, and closely influences human health [6]. Yang et al. conducted extensive research on bioclimatic architectures and proposed that architectural design strategies should account for climatic conditions [4,7]. This is also known as the "design with climate" approach. Prior research on traditional dwellings has typically focused on indoor thermal environment testing [8,9], dwelling evolution [10,11], architectural language [12,13], and construction technology and structural design [14,15]. However, limited research has been conducted on human comfort in the indoor environments of traditional dwellings, especially with respect to bioclimatic architecture [16]. Thermal comfort, lighting comfort, and acoustic comfort have all been identified as important parameters for evaluating the environmental comfort provided by a building [17]. Zhao et al. discovered that the indoor thermal environment of traditional dwellings is not ideal due to a lack of scientific design $[18,19]$. However, it remains necessary to conduct holistic and systematic research on traditional dwellings to evaluate the climate responsiveness of their construction and apply successful traditional design strategies in the design of healthy modern residential buildings.

A large proportion of residential buildings in China are rural dwellings. Although ASHRAE 55 [20] is the internationally accepted standard for thermal environmental comfort, domestic and foreign scholars have conducted many thermal comfort field tests and concluded that the actual thermal sensation of occupants in indoor thermal environments considerably differs from predictions based on ASHRAE 55 [20]. The main reasons for this difference lay in the behavioral adaptability and psychological expectation of residents regarding their climate [21]. Therefore, research on the comfort of local residents is of great significance to the implementation of local residential building codes.

This study accordingly performed a holistic and comprehensive evaluation of the climate-responsive strategies of traditional dwellings in southern Zhejiang, China. The effects of the climate adaptive functions of these buildings on the microclimate and occupants' response to the indoor environment were thus reassessed. This study not only served as a reference for devising local regulations for the construction of healthy habitats in southern Zhejiang but also provided a scientific basis for the preservation of the climate adaptive technologies of traditional dwellings.

\subsection{Study Scope}

Climate consists of macroclimate, mesoclimate, local climate and microclimate, according to the influence of the statistical average state of the atmosphere as the spatial scale [22-24]. Local climate refers to the climate of comparatively small regions with fairly uniform natural conditions $[25,26]$. In order to examine the local climate adaptive architecture of dwellings, the indoor environmental quality (IEQ) of traditional rural dwellings and occupants' health and environmental satisfactions were investigated. In 2016, six work stations were established in the six typical geographical environments of the Zhejiang Province. Sample villages were selected as research projects to reflect the various geographical environments. Zhejiang Province is divided into six typical geographical environments, each with its own unique topographic setting: ZJ Plain, West ZJ Hill, East ZJ Hill, Central Jin-qu Basin, South ZJ Hill, and South-East Coastal Plain and Island. The characteristics of the traditional architecture in each of these geographical environments reflect the climatic conditions of each location.

The result indicated that the alpine climate in southwestern Zhejiang, (specifically Jinyun County, Lishui) is the most complex and extreme among the six investigated geographical environments., as it reflects the cumulative effect of geographical and climatic factors [27]. "Stereoscopic climate" consists of different climate types simultaneously distributed within a given region, relating to seeing space three-dimensionally [28]. Thus, a further in-depth study should be based on the microclimate as the smaller size of the local size climate. "Microclimate" is defined as the distinctive conditions within a region that is affected by various local factors, which result from small-scale differences in the earth's topography [26,29]. Heyang Village and Danzhi Village, which are located at the foothill and mid-slope, respectively, of the alpine climate zone of southern Zhejiang, were selected for research. In Zhejiang Province, the warm season is long, and the humidity is high, with no severe cold season; 
traditional dwellings are mainly designed for the warm season [30]. Previous studies have focused on summer and winter season [31]; this study, however, investigated the little-known plum rain season in early summer due to its unique conditions.

This study consisted of three phases: an investigation of the physical state of the ancient dwellings in the subject villages, on-site measurements of their physical environments, and survey questionnaires of their residents, detailed as follows:

1. First, the layout environment and architectural design of the dwellings were investigated.

2. Then, the indoor and outdoor physical environments were monitored on-site, and the measured parameters were analyzed based on the thermal, lighting, and acoustic environments.

3. Finally, a survey was conducted to determine the occupants' responses to their thermal, lighting, and acoustic environments.

The differences in the architectural strategies for different stereoscopic climates in the same microclimate region were thus explored under the natural operating conditions of the subject buildings to verify the rationality and practicability of the climate responsive design of traditional dwellings in southwestern Zhejiang.

\subsection{Study Objectives}

This study comprehensively evaluated the differences between the microclimate responsiveness of dwellings and the realized IEQ to achieve the following research objectives:

1. Define the construction environment of dwellings for the geographical and climatic conditions in southwestern Zhejiang.

2. Taking Heyang Village and Danzhi Village as case studies, discuss the climate adaptive design strategies of site selection, community layout, the courtyard, roof, materials, and design details of the villages, in order to gain insight into the traditional climate adaptive practices of traditional dwellings.

3. Analyze the indoor thermal environment in plum rain season to determine the effectiveness of the climate-responsive strategies in terms of factors, such as temperature, relative humidity $(\mathrm{RH})$, and wind speed, and determine whether the lighting and acoustic qualities of the indoor environments provided by traditional construction methods meet the ASHRAE 55 standard.

4. Analyze the dwelling occupants' experience and satisfaction of their physical living environment and establish the thermal, lighting, and acoustic IEQ resulting from the climate responsive measures of the dwellings using a questionnaire. Identify the challenges posed by the physical environment of traditional dwellings in the region.

5. Review the differences between regional microclimates in the same climatic zone and explore more optimized passive technologies for indoor environmental comfort.

The results of this study supported local architectural initiatives, such as the "Construction Regulation for Beautiful Villages in Zhejiang Province" [32] and the "Assessment Standard for Healthy Buildings" [33], and could provide supplementary guidelines for the construction of new residential buildings in various stereoscopic climates. The results of this study served as a reference for the construction of healthy habitats in southwestern Zhejiang and provided a scientific basis for the preservation and innovation of the climate adaptive technologies used in traditional dwellings.

\section{Methodology}

\subsection{Geographical Environment of the Study Area}

Jinyun County, Zhejiang, is located in the southwestern region of Zhejiang Province. The area is mountainous with limited plains. Both Heyang Village and Danzhi Village are ancient villages with histories stretching back 1100 years. The water system and roads mostly retain the design features 
typical of villages constructed in the Yuan Dynasty. The region has a low-to-mid landform, and the subject villages are $8 \mathrm{~km}$ apart with an altitude difference of $100 \mathrm{~m}$ (Table 1).

Table 1. Village conditions and survey population.

\begin{tabular}{cccc}
\hline Village & Geographical Conditions & Average Elevation & Surveyed Amount \\
\hline Heyang & flat plain & $150 \mathrm{~m}$ & 53 people \\
Danzhi & hilly & $260 \mathrm{~m}$ & 50 people \\
\hline
\end{tabular}

Heyang Village, shown in Figure $1 \mathrm{a}, \mathrm{b}$, is located on flat terrain in a basin in the northwest hilly region of Jinyun County and is surrounded by mountains on all sides. It has an average elevation of $150 \mathrm{~m}$. The village faces southeast, overlooking a stream that flows from west to east. The ancient village form is relatively preserved, and this village has been declared a "Historical and Cultural Site Protected at the Provincial Level."

Danzhi Village, shown in Figure 1a,c, is located in the hilly western area of Jinyun County, backed by hills in the northeast and surrounded by water on three sides. It has an average elevation of $260 \mathrm{~m}$. The village is located in the foothills of a mountain and has been constructed partially up the side of this mountain. Due to its relatively limited communication with the outside world, this village has retained the traditional dwellings that are unique to the local ecology.

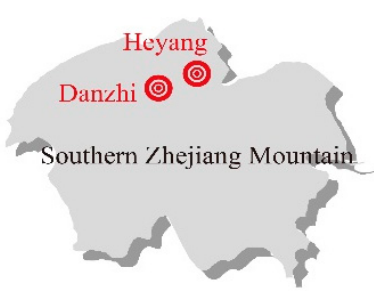

(a)

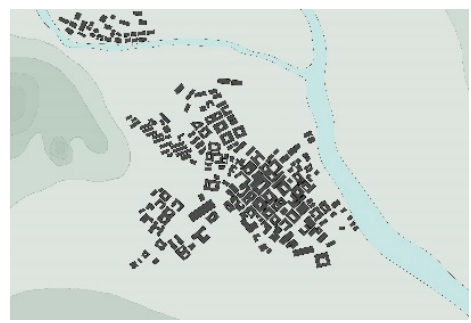

(b)

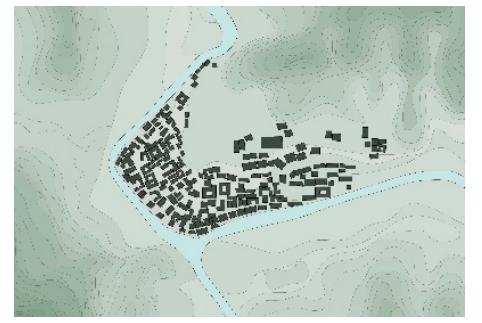

(c)

Figure 1. (a) Location of sample villages and the layouts of (b) Heyang and (c) Danzhi.

\subsection{Study of Climate Description}

Meteorological parameters closely related to architecture include solar radiation, air temperature, humidity, natural light, wind, and precipitation. Jinyun County has a subtropical monsoon climate. According to the "Building Climate Demarcation Standard" of China [34], it is classified as a "Hot Summer and Cold Winter" climate zone. The average annual precipitation is $1473 \mathrm{~mm}$ [35], the annual number of precipitation hours constitutes greater than $50 \%$ of the year [36], and the annual average wind speed is approximately scaled 1 . However, typhoons are frequent and reach wind speeds of scale 6 to 8 in the low mountain range and scale 9 to 10 in the high mountain range. Early summer is called the plum rain season, in which high humidity and continuous rains are experienced, and typhoons and local thunderstorms are frequent in midsummer. Intense solar radiation, high temperature and humidity, rainy conditions, and hail mainly occur between March and August [7,37]. The main meteorological parameters of Jinyun County are summarized based on data from the Zhejiang Meteorological Observatory and Lishui Meteorological Observatory, as shown in Figures 2 and 3. These data indicate that the hottest month also has very high humidity. 

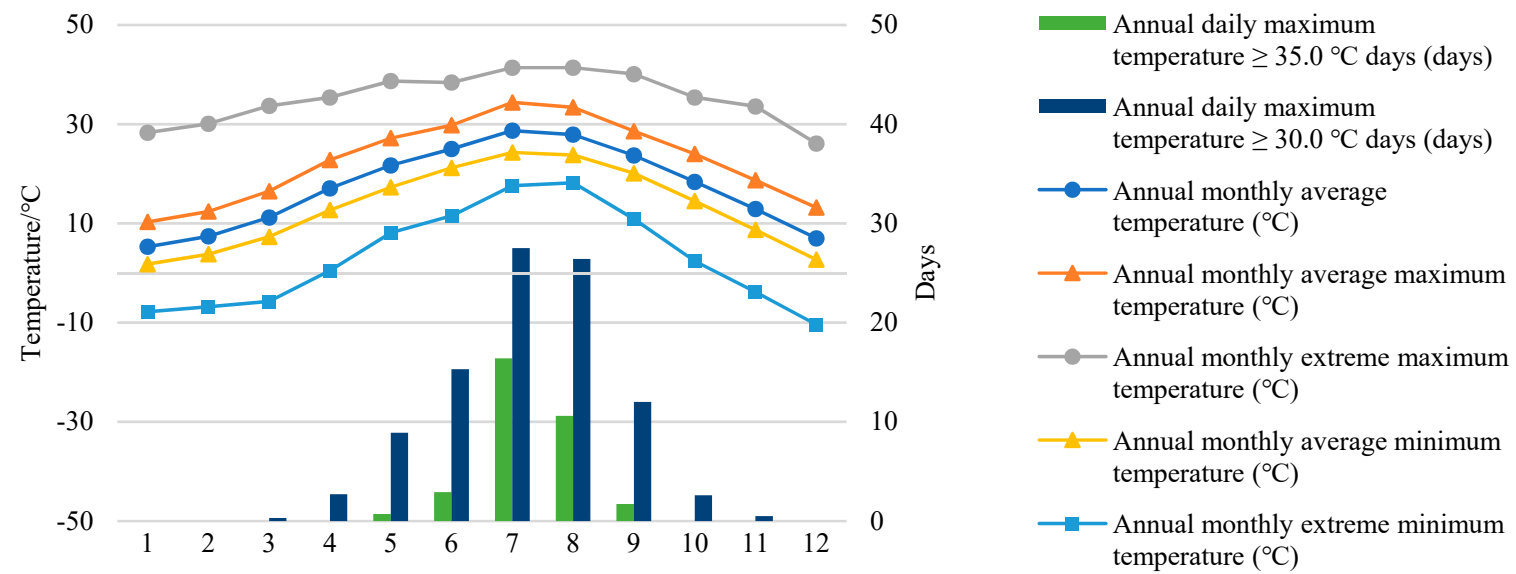

Figure 2. Monthly temperature and relative humidity (RH) in Jinyun County, Zhejiang Province, China.
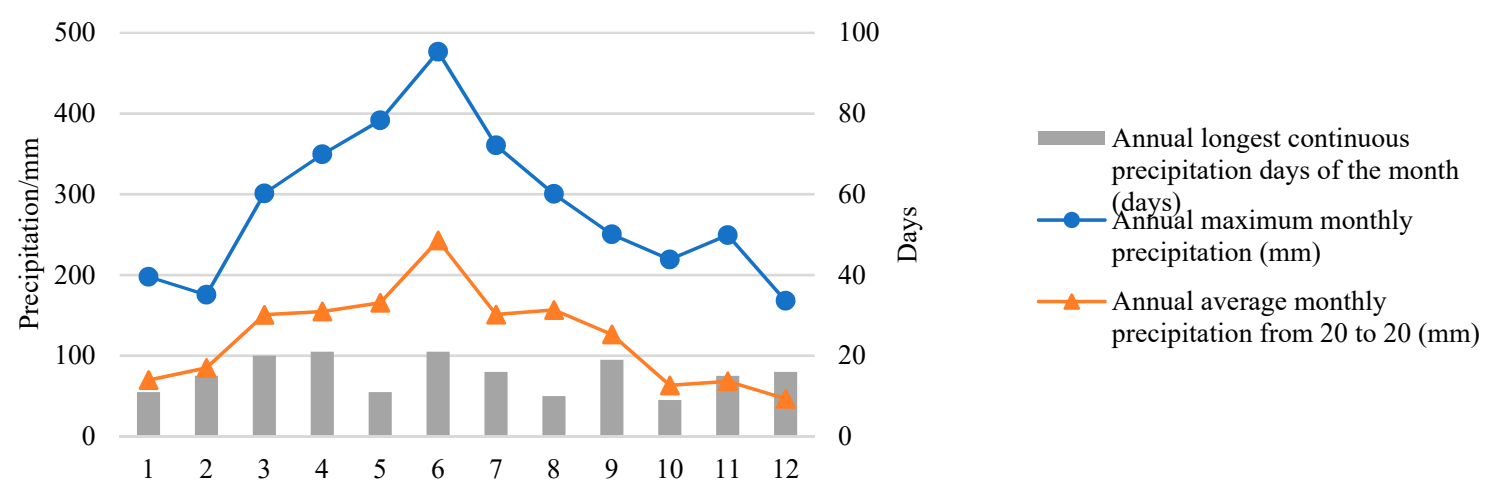

Figure 3. Monthly precipitation data for Jinyun County, Zhejiang Province, China.

\subsection{Study Microclimate and Climate Responsive Architectural Strategies}

Climate responsive design strategies refer to the approach of utilizing favorable climate elements and offsetting adverse climatic elements [38]. From a climate perspective, climate-responsive architectures not only respond to climatic factors through the site selection of the building, the layout of the community, the building unit, and the details of building design but also consider the impact of climatic factors on the indoor physical environment and comfort level and provide possibilities for occupants' behavioral adjustment in their architectural design [39,40].

This paper comprehensively discussed the technical aspects of the climate responsive design strategies of ancient dwellings in southern Zhejiang, including layout, orientation, spacing, wind protection, heating and cooling of buildings, and natural ventilation. These strategies were evaluated at the building complex, single-structure design, and local component developmental levels. The effects of climatic factors on the design of ancient dwellings, as well as the indoor comfort corresponding to the thermal environment, were also presented.

\subsubsection{Climate and Spatial Structure}

(1) Site selection and layout: Heyang Village is located on flat terrain, and the layout of the buildings is parallel to and linearly distributed along the river. Some areas form a relatively open space, and the majority of the buildings are courtyard houses, while others have a linear structure. There are narrow avenues between the buildings. Danzhi Village is built around the river. It is backed by hills on one side and surrounded by water on the other three sides. The village houses are distributed along the hillside of the southern foothills in a U-shaped fashion. The buildings are more densely arranged in Danzhi than in Heyang, forming a village pattern that faces the sun to the south and shelters the village from the mountain winds from the north. Both villages are built close to a body of water to ensure 
sufficient sunshine and wind protection. Reviewing Figures 1 and 4, it is clear that the geographical environment has a significant influence on the distribution of dwellings within these settlements.

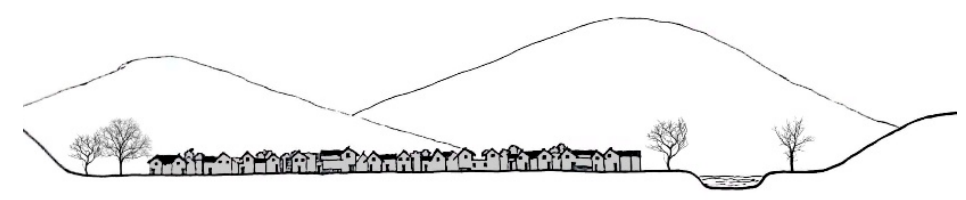

(a)

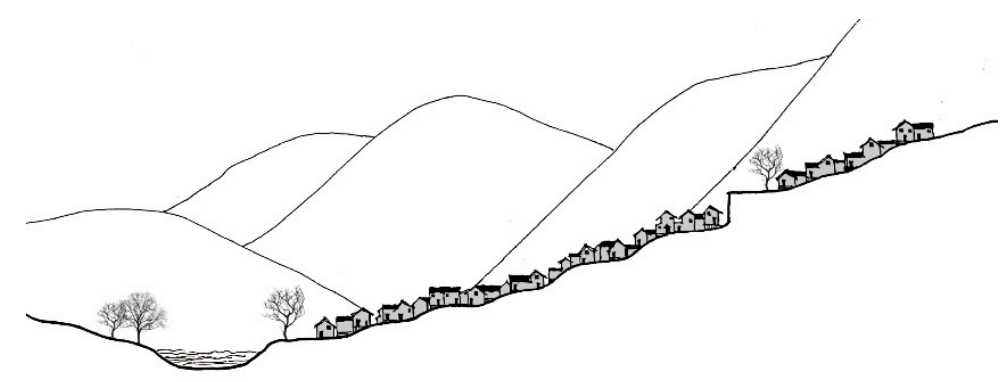

(b)

Figure 4. Site elevations of (a) Heyang and (b) Danzhi.

(2) Courtyards: To manage the year-round high humidity, summer heat, and typhoons, the dwellings in the two subject villages have typically adopted a layout with a small inner courtyard. This arrangement is able to cope with the variations in the external climate. Isolation from the external environment allows for insulation and dehumidification; thus, the environment inside the courtyard is used to adjust the microclimate of the dwelling. By forming an enclosed microenvironment, the indoor and outdoor temperature difference generated by solar radiation creates thermal pressure. The draft created by this thermal pressure removes heat and extracts the hot and humid air from the rooms, reducing the indoor temperature. In the summer, the courtyard blocks sunlight and reduces the solar radiation entering the rooms, reducing the air temperature in the courtyard to provide a cooler space. The space above the courtyard is exposed to the sun, so the temperature above the courtyard is higher than that inside the courtyard; as the hot air rises, the pressure in the courtyard is reduced and generates a draft in the surrounding dwelling. The interior hot air flows out into the courtyard and creates a stacking effect. The courtyard, therefore, not only promotes dwelling ventilation but also has a cooling effect (Figure 5). The main courtyard-based dwelling form in Heyang Village is the 28-room double courtyard house, which takes advantage of the "drafting" effect of double courtyards. The main courtyard-based dwelling form in Danzhi Village is the 16-room single courtyard house, which has distinct construction features used in mountainous terrains. Because of the pronounced topographical wind effect and the narrow available land, the courtyards are smaller and more enclosed with a minimal external opening area. As a result, they have a higher capability for adjusting the microclimate inside the building.

(3) Cooling avenues: These narrow avenues are present in both villages (Figure 6a). The selfshading of the buildings prevents direct sunlight on the facades fronting these avenues, lowering the local temperature. Thermal pressure ventilation is created by the temperature difference between the cooler avenue and the edge of the village. Concurrently, when the indoor temperature is high, the cooling capacity of the thick walls and ground in the cooler avenues removes heat from the interior of the buildings. Thus, cooling avenues have a climate-adaptive cooling effect. 


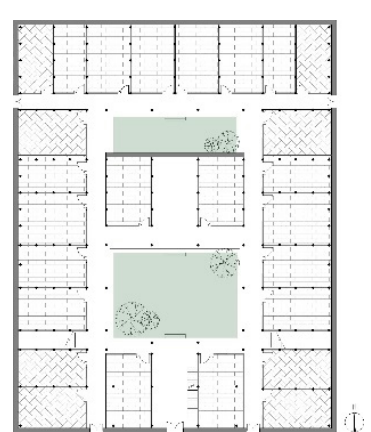

(a)

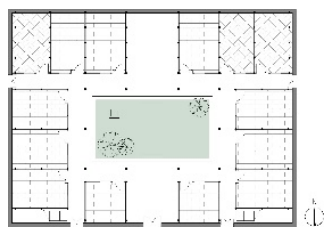

(b)

Figure 5. Floor plans of typical dwellings in (a) Heyang and (b) Danzhi.

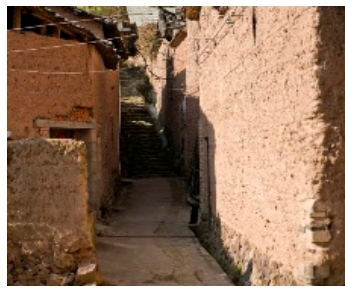

(a)

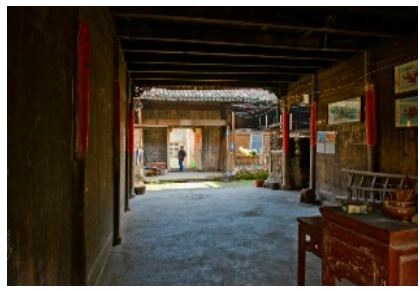

(b)

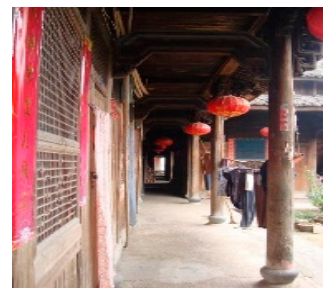

(c)

Figure 6. Typical (a) cooling avenue, (b) living room, and (c) corridor views of subject buildings.

\subsubsection{Climate and Spatial Form}

(1) Heat radiation and rain proofing: To mitigate the effects of strong solar radiation, eaves are installed on the first and second floors facing the inner courtyard. The second floor is mainly used for guest rooms and storage. These overhanging eaves provide shade, while the attic acts similar to a ventilated roof to serve as a thermal buffer between the living space on the first floor and the outside. The eaves installed on the roof of the first floor are larger than those on the second floor, and they project over the corridor to prevent direct heating of the walls. The corridor space created under these eaves also provides insulation, shade, rain protection, and heat buffering between the indoor and outdoor spaces. The eaves of Heyang Village are broad, whereas the eaves of Danzhi Village are small (Figure 6b,c).

(2) Windproofing and wind guiding: A concave central hall eliminates an exterior wall and extends into the courtyard, forming a semi-outdoor space. The courtyard and central hall form a coherent design structure that acts as a natural ventilation system. Open on one side to the courtyard, the central hall provides an ample interior space that results in a temperature difference between the upper and lower spaces and creates thermal pressure ventilation that extracts the hot and humid indoor air to the outside. The roof is not insulated, and the gaps between the tiles help to ensure proper ventilation (Figure 7).

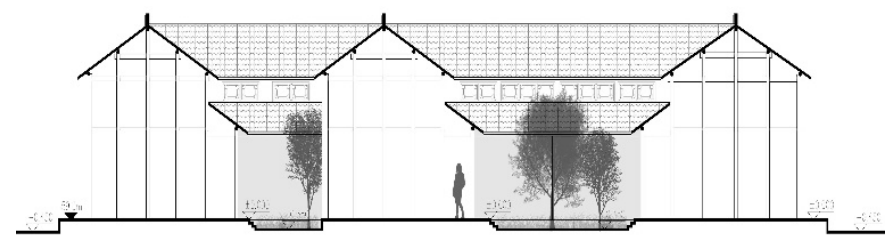

(a)

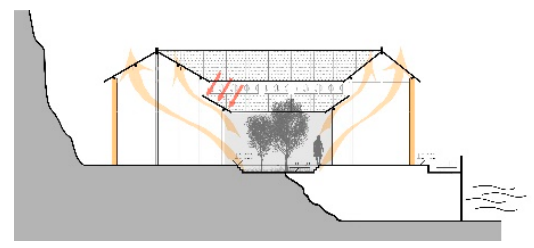

(b)

Figure 7. Building sections in (a) Heyang and (b) Danzhi. 


\subsubsection{Traditional Dwelling Materials}

The envelope and window designs of the dwellings in the subject villages were selected to provide a constant interior thermal environment.

(1) Envelope: The exterior walls of the dwellings in both villages are made of thick rammed earth that has a small heat transfer coefficient, very high resistance to temperature change, and provides heat insulation and storage. The interior walls facing the inner courtyard are made of lightweight wood and have a higher heat transfer coefficient than the thick rammed earth. Slats in the wooden walls also facilitate heat dissipation. As a result, the internal thermal environment is more comparable with the microclimatic air temperature of the courtyard than with the exterior climate. In Danzhi Village, the foundation of the exterior walls is made of stone to avoid moisture infiltration into the wall base. Envelope material is used in insulation in the two subject villages to achieve effective heat insulation and dissipation effects. The exterior walls of Danzhi Village are not tall to minimize the outdoor contact area for higher resist storms and less energy consumption.

(2) Windows: Dwellings in both villages have small window openings on the exterior walls and large window openings on the interior walls facing the inner courtyards to isolate the interior from the outdoor climate and utilize the inner courtyards for lighting and ventilation (Figures 8 and 9).

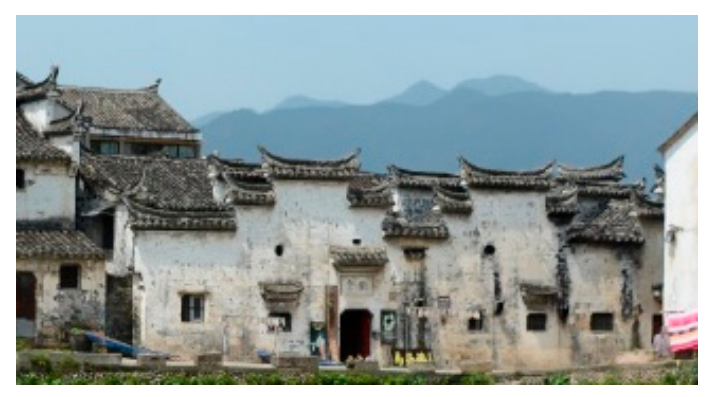

(a)

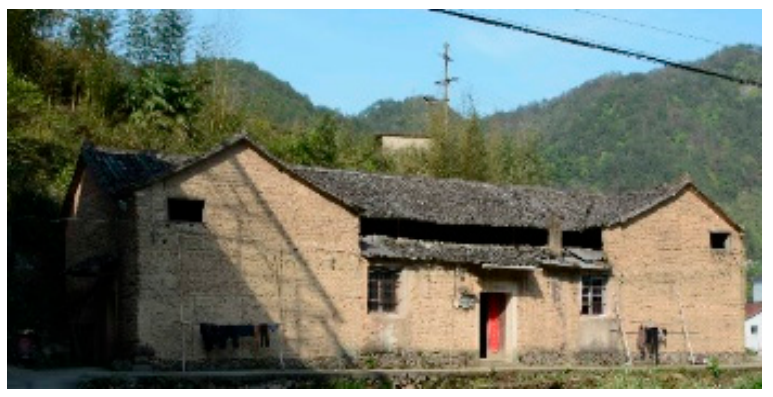

(b)

Figure 8. Exterior facades in (a) Heyang and (b) Danzhi.

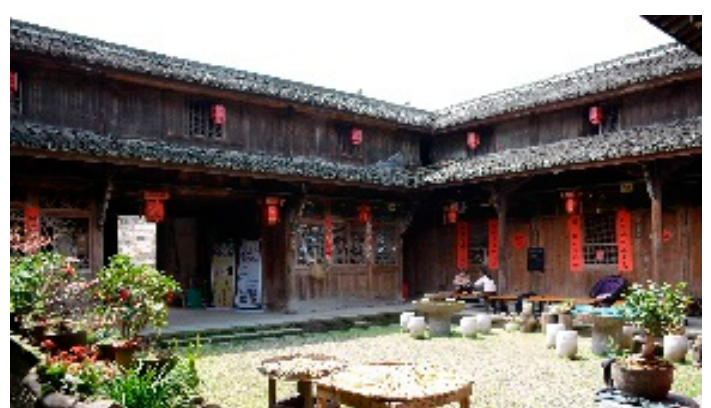

(a)

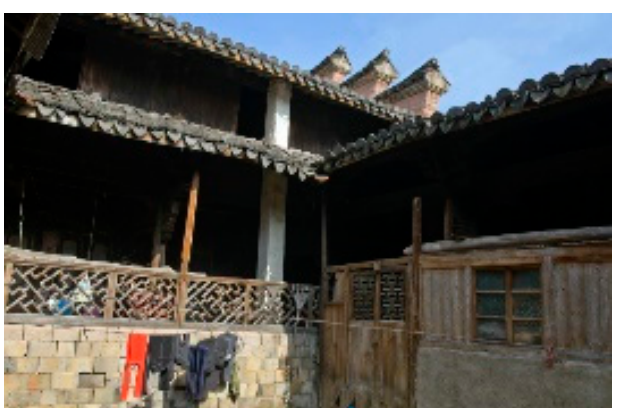

(b)

Figure 9. Interior courtyard facades in (a) Heyang and (b) Danzhi.

In summary, the traditional dwellings in southern Zhejiang Province promote the natural ventilation of indoor and outdoor air while protecting against weather, such as typhoon damage, using a combination of architectural space, facades, and structural members. The envelope formed by the thick exterior walls and small or minimal window openings stabilize the internal thermal environment. The courtyard serves as a transitional space between the indoors and the outdoors and provides ventilation, lighting, heating, shading, wind protection, and drainage of the indoor spaces. 


\section{Experimental Measurements and Data Analysis}

\subsection{Outdoor Environmental Conditions}

\subsubsection{Annual Climate Data}

The climatic characteristics of Jinyun County include high rainfall amounts, high temperature, few sunshine hours, and humid conditions. On average, 44\% a year are rainy days, as shown in Figure 10. Thus, enhanced lighting, heat protection, ventilation, and wind and rain protection are crucial passive design strategies in the subject buildings. Of particular note, the plum rains in June provide the heaviest rainfall and the longest rainfall duration. Together with high temperatures and low wind speeds (shown in Figure 11), this considerable rainfall is unfavorable to the thermal environment of the buildings.

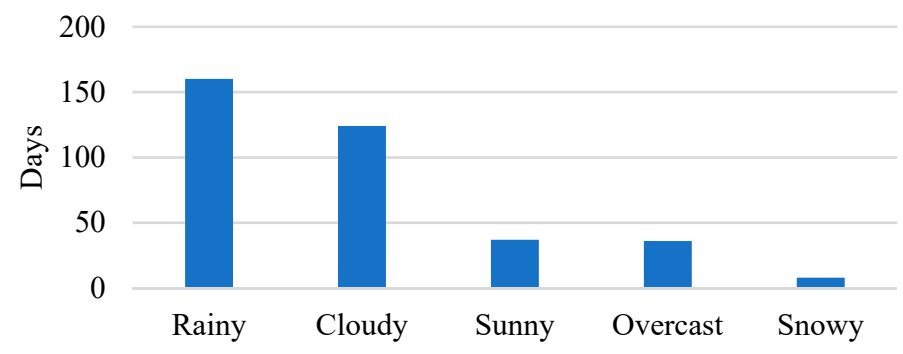

Figure 10. Distribution of different weather days in a year in Jinyun County.

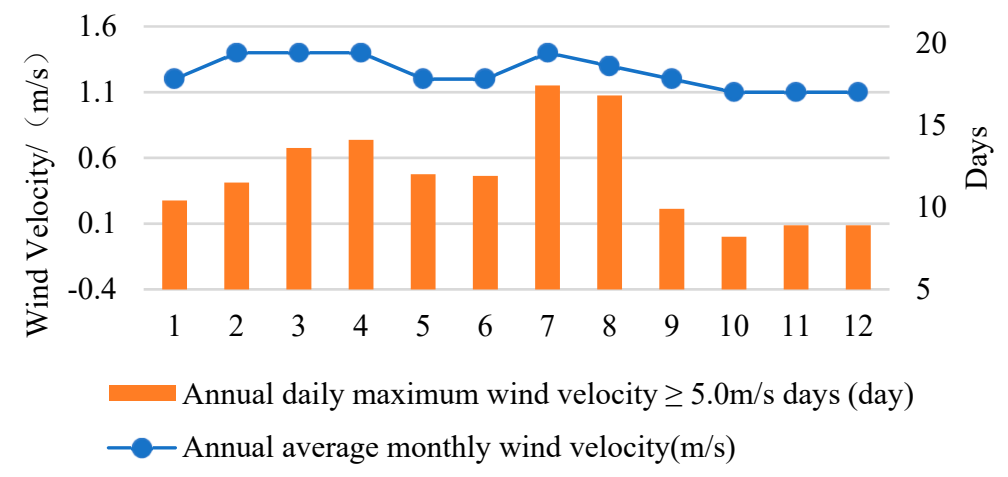

Figure 11. Wind speeds each month in Jinyun County.

The average meteorological data of Jinyun County in June is shown in Table 2 over 20 years. According to Table 2, which is measured based on data over 20 years, the average RH in June is $88.2 \%$, and the highest air velocity is $1.2 \mathrm{~m} / \mathrm{s}$.

Table 2. Average meteorological parameters for Jinyun County in June (1990-2010).

\begin{tabular}{cccccc}
\hline $\begin{array}{c}\text { Relative } \\
\text { Humidity }\end{array}$ & $\begin{array}{c}\text { Maximum } \\
\text { Temperature }\end{array}$ & $\begin{array}{c}\text { Extreme } \\
\text { Temperature }\end{array}$ & $\begin{array}{c}\text { Maximum } \\
\text { Precipitation }\end{array}$ & $\begin{array}{c}\text { Maximum } \\
\text { Raining Days }\end{array}$ & Air Velocity \\
\hline $88.2 \%$ & $29.8^{\circ} \mathrm{C}$ & $35^{\circ} \mathrm{C}$ & $477 \mathrm{~mm}$ & $21 \mathrm{~d}$ & $1.2 \mathrm{~m} / \mathrm{s}$ \\
\hline
\end{tabular}

\subsubsection{Data Acquisition}

The stereoscopic climate in southern Zhejiang is very pronounced in the hilly regions and mountainous terrain. The variability and stability of the climate elements in this region are complex, and their combinations are diverse. The alpine climate is a stochastic climate system [27], meaning that it is variable and random. Additionally, as indicated by the climograph in Figure 3, the amount of 
continuous precipitation in June, known as the plum rain season, is quite high. Accordingly, this study conducted additional on-site environmental measurements in the ancient dwellings of the two subject villages in June in order to attain realistic IEQ data. The measurement of indoor and outdoor physical environment parameters was conducted during typical plum rain season weather with continuous rainfall day and night from June 19 to June 26, 2019. During this season, all windows of the dwellings were open according to the living habits of the residents. According to the "breathing zone" definition of ASHRAE 129 [41], the indoor air temperature, RH, air velocity, illuminance, and noise level were measured $1.1 \mathrm{~m}$ above the floor in the center of the room. These measurements were divided into four periods: morning (waking up to 11:00), midday (11:00 to 17:00), evening (17:00 to bedtime), and night (bedtime to waking up). The measurements were conducted continuously for 24 hours in bedrooms, living rooms, and other main rooms, as well as outdoors. The measurement instruments and their parameters are provided in Table 3. These IEQ data served as a basis for the cross-sectional analysis of the occupancy satisfaction surveys discussed in Section 3.3.

Table 3. Measurement parameters and instruments used to determine environmental quality.

\begin{tabular}{ccccc}
\hline \multirow{2}{*}{ Items } & Parameters & Instrument & $\begin{array}{c}\text { Instrument } \\
\text { Precision }\end{array}$ & $\begin{array}{c}\text { Sampling } \\
\text { Interval }\end{array}$ \\
\hline \multirow{2}{*}{ Thermal environment } & Air temperature & Aosong Gsp 958 & $\pm 0.2{ }^{\circ} \mathrm{C}$ & $30 \mathrm{~min}$ \\
\cline { 2 - 5 } & Air RH & Aosong Gsp 958 & $\pm 0.05{ }^{\circ} \mathrm{C}$ & $30 \mathrm{~min}$ \\
\cline { 2 - 5 } & Air velocity & Tjhy Fb-1 & $\pm 0.1{ }^{\circ} \mathrm{C}$ & $30 \mathrm{~min}$ \\
\hline Lighting environment & Natural lighting illumination & Xyi Tes-1330A & $\pm 3 \%$ & $30 \mathrm{~min}$ \\
\hline Acoustic environment & Noise & Xm 804 & $\pm 1.5 \mathrm{db}$ & $30 \mathrm{~min}$ \\
\hline
\end{tabular}

\subsubsection{Thermal Comfort Evaluation Criteria}

Various adaptive comfort models have been developed to serve as comfort standards in different countries and areas, such as ASHRAE 55 [20] and China National Standard GB/T 50785-2012 [42]. Previous research has considered adaptive thermal comfort to be related to the outdoor temperature, informing the IEQ parameter guideline ranges for adaptive thermal comfort specified along with the measurement ranges in Table 4 .

Table 4. Summary of measured indoor environmental quality (IEQ) data and the guidelines adopted in this study.

\begin{tabular}{cccccc}
\hline \multirow{2}{*}{$\begin{array}{c}\text { IEQ Measurement } \\
\text { Indoor }\end{array}$} & \multicolumn{3}{c}{ Plum Rain Season } & & \multirow{2}{*}{ Guideline } \\
\cline { 2 - 5 } & \multicolumn{2}{c}{ Heyang } & \multicolumn{2}{c}{ Danzhi } & \\
\cline { 2 - 5 } & Mean & STD & Mean & STD & \\
\hline Temperature $\left({ }^{\circ} \mathrm{C}\right)$ & 26.13 & 1.36 & 25.86 & 1.11 & $\begin{array}{c}\text { Between 23 and 28 }{ }^{\circ} \mathrm{C} \\
\text { (ASHRAE 55-2013 [20]) }\end{array}$ \\
\hline Relative humidity (\%) & 93.39 & 1.54 & 95.39 & 1.21 & $\begin{array}{c}\text { Less than 65\% } \\
\text { (ASHRAE 55-2013 [20]) }\end{array}$ \\
\hline Air velocity @ 1.1 m (m/s) & 0.089 & 0.028 & 0.085 & 0.012 & $\begin{array}{c}0.2 \text { m/s or less } \\
\text { (ASHRAE 55-2013 [20]) }\end{array}$ \\
\hline Illuminance (lux) & 64.85 & 47.69 & 74.25 & 67.16 & $\begin{array}{c}\text { Greater than 300 lux } \\
\text { (GB/T 50033-2013 [43]) }\end{array}$ \\
\hline Acoustic decibel (dBA) & 54.40 & 7.32 & 47.50 & 7.22 & $\begin{array}{c}\text { Less than 40 dB } \\
\text { (ASHRAE 55-2013 [20]) }\end{array}$ \\
\hline
\end{tabular}




\subsection{Analysis of Thermal Conditions in Summer and Rainy Seasons}

\subsubsection{Test Analysis}

The changes in the humidity, temperature, and air velocity data over the measurement period were analyzed with the following results.

(1) Humidity: As shown in Table 2 and Figure 12, during the plum rain season measurement period, the average outdoor humidity in Heyang Village and Danzhi Village was 95.19\% and 95.94\%, respectively. The indoor humidity during the day was maintained between $83 \%$ and $93 \%$, and the daytime indoor RH was higher than the daytime outdoor $\mathrm{RH}$. The indoor and outdoor $\mathrm{RH}$ in the two villages thus exceeded the ASHRAE 55 humidity comfort range of less than 65\%. Even during days without solar radiation, evaporation was unable to reduce the humidity. Consequently, the RH of the two villages remained high during both daytime and nighttime, the indoor and outdoor humidity was comparable, and so the high humidity could be considered severe. Indeed, due to continuous rainfall, the humidity was even higher during the day than at night. In Danzhi Village, the indoor and outdoor humilities were observed to be consistently high throughout the day because of tree shading (Figure 12). Indeed, these results confirmed the existence of severe indoor humidity in the two villages during the plum rain season, with the humidity in Danzhi Village being more extreme. This was mainly due to the high temperature and humidity of the dense forest environment of Danzhi Village, which results in a high moisture retention capacity and limited dehumidification efficiency. Residents keep windows open throughout the day; as a result, the indoor humidity and outdoor humidity were equal.
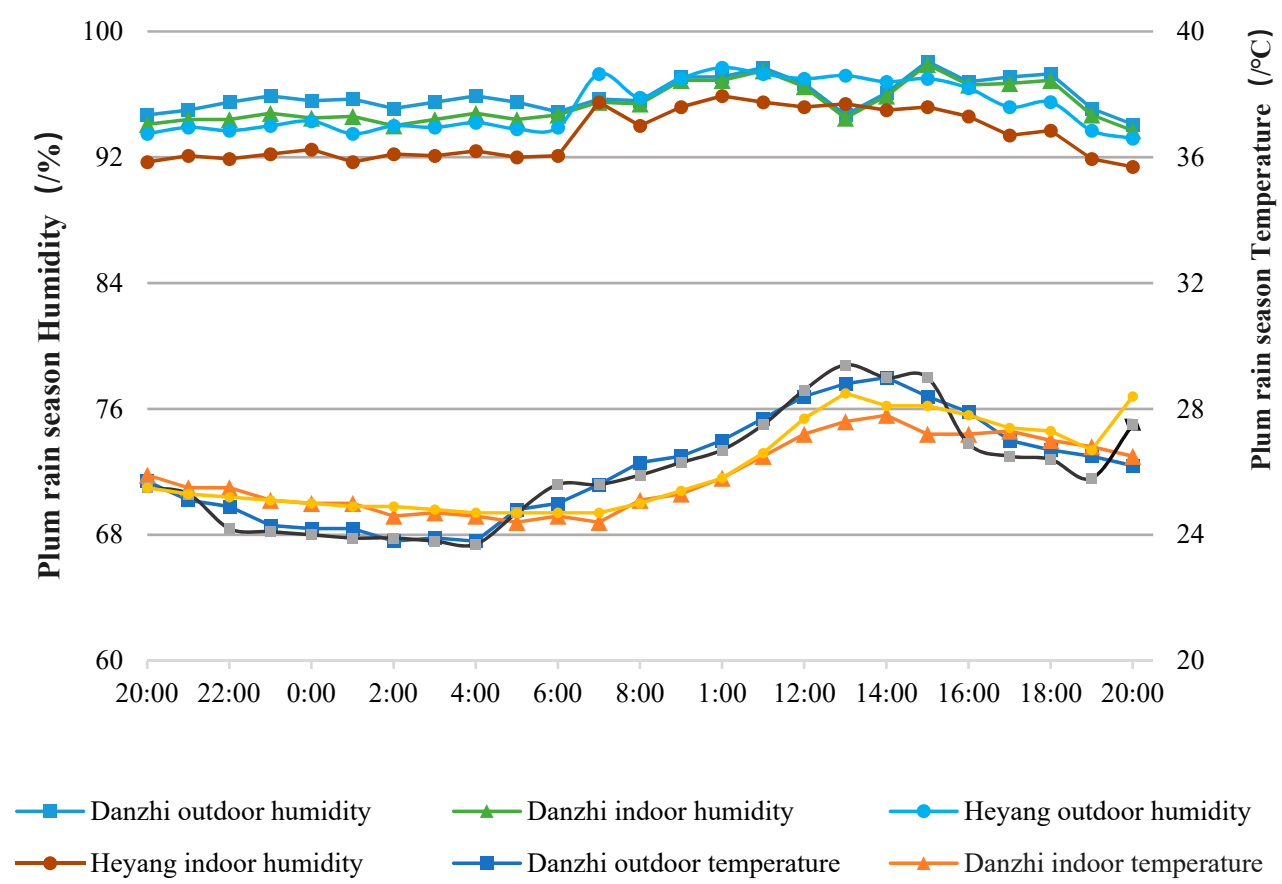

Figure 12. Average temperature and RH in Heyang and Danzhi villages over $24 \mathrm{~h}$ during the plum rain season.

(2) Temperature: As shown in Table 2 and Figure 12, during the plum rain season measurement period, the average outdoor temperature in Heyang Village and Danzhi Village was $26{ }^{\circ} \mathrm{C}$ and $26.1^{\circ} \mathrm{C}$, respectively, the maximum outdoor temperature was $29.4^{\circ} \mathrm{C}$ and $29^{\circ} \mathrm{C}$, respectively, and the minimum outdoor temperature in both villages was $23.7^{\circ} \mathrm{C}$. The average indoor temperature in Heyang Village and Danzhi Village was $26.1^{\circ} \mathrm{C}$ and $25.9^{\circ} \mathrm{C}$, respectively. From 12:00 to 15:00, the outdoor temperature of the two villages exceeded the ASHRAE 55 temperature comfort standard, defined in Table 2. The indoor temperature in Heyang Village exceeded the comfort standard from 13:00 to 15:00, but 
stayed within the comfortable temperature zone during the remaining periods, whereas the indoor temperature in Danzhi Village was within the comfort standard throughout the day. The indoor and outdoor temperatures were comparable because the humidity in the buildings was so high that the insulation effect from the building envelope was insignificant.

(3) Air velocity: The average indoor airflow measured during the plum rain season is shown in Table 2 and Figure 13, showing no significant difference in the airflow in Heyang Village and Danzhi Village; the airflow in both villages was concentrated in the low wind speed range, varying from 0.06 to $0.14 \mathrm{~m} / \mathrm{s}$ with an average of $0.1 \mathrm{~m} / \mathrm{s}$. The room temperature and humidity could not, therefore, be effectively reduced as the airflow was unable to facilitate convective flow. Accordingly, adequate ventilation was not achieved, and heat dissipation from the human occupants was not realized. Thus, thermal comfort was poor. Furthermore, there was no significant difference between indoor and outdoor temperatures to generate thermal pressure ventilation. Still, the wind speed in the central hall (living room) was higher than in the bedrooms as the semi-open central hall was connected to the courtyard. Because of the smaller area and lower height of the courtyards in Danzhi Village, the ventilation was less effective than in Heyang Village. In summary, during the plum rain season, dwellings in both villages were unable to realize efficient ventilation. Nonetheless, the ventilation was better in Heyang Village than in Danzhi Village.

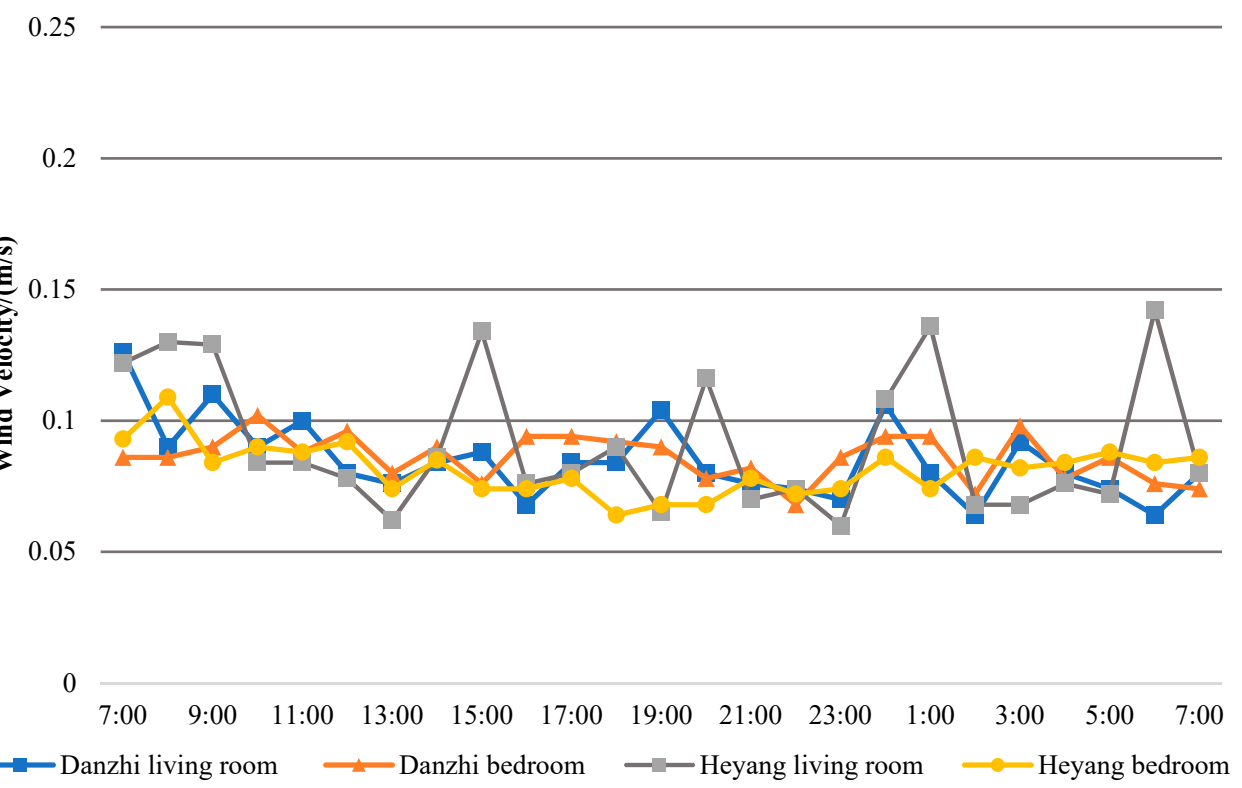

Figure 13. Average air velocity in Heyang and Danzhi villages over $24 \mathrm{~h}$ during the plum rain season.

\subsubsection{Thermal Comfort Analysis}

The indoor thermal environment assessment criteria applied in this study were based on the predicted mean vote (PMV) and the percentage of people dissatisfied with the environment (PPD) indices. ASHRAE 55 defines conditions that are considered satisfactory for a specific percentage of users, including calculation methodologies for thermal comfort based on PMV/PPD. This standard is based on Fanger's PMV, which predicts the mean thermal sensation of a group of people, and the PPD. The factors considered in these criteria include activity level (metabolic rate), occupant clothing (degree of insulation), temperature, thermal radiation, humidity, and airspeed (see also Chinese Standard GB/T 50785-2012 [42]).

The values of the relevant parameters in the PMV-PPD calculation were as follows:

- Residents in the region mainly sit and are at rest indoors, and the metabolic rate of the human body was set to 1 met. 
- The average thermal insulation from the summer clothing of men and women was 0.5 clo.

- Based on the average measured value, the indoor air velocity was set to $0.1 \mathrm{~m} / \mathrm{s}$.

- The mean radiant temperature (MRT) was set to the average temperature of the six interior surfaces of the building envelope, such that MRT $=\sum\left(A_{n} T_{n}\right) / \sum A_{n}$, where $A_{n}$ (in $\left.\mathrm{m}^{2}\right)$ is defined as the visible area of surface $n$, and $T_{n}\left({ }^{\circ} \mathrm{C}\right)$ is the surface temperature of surface $n$.

- Residents occupy the central hall during the day from 7:00 to 23:00 and the bedrooms during the night from 23:00 to 7:00 the next day; the temperature and humidity of each room were measured for each period, as detailed in Section 3.1.2.

The PMV curve (Figure 14) and associated linear regression equation for the plum rain season were calculated using the linear fitting of the PMV of the indoor living room and the operating temperature $t_{o p}$ on a typical measurement day (June 20th) in the plum rain season, yielding:

PMV $=0.4021 t_{o p}-10.10$ (Heyang Village),

PMV $=0.4129 t_{o p}-10.30$ (Danzhi Village).

The recommended PMV range of -0.5 to +0.5 specified in ISO 7730 applies to air-conditioned buildings. For naturally ventilated rooms in the "Hot Summer and Cold Winter" climate zone in China, the applicable PMV values are between -1 and +1 [41]. Then, based on the linear regression PMV equation and applying $-1 \leq \mathrm{PMV} \leq+1$ as the thermal comfort range, the predicted upper limit of resident-acceptable temperature in Heyang Village and Danzhi Village during plum rain season was determined to be $27.6^{\circ} \mathrm{C}$ and $27.37^{\circ} \mathrm{C}$, respectively, and the humidity level was very high. During the measurement period, the PMV values were greater than 1 and exceeded the predicted comfort range from 13:00 to 14:00 in Danzhi Village and from 12:00 to 15:00 in Heyang Village. The PPD variation was $28 \%$ to $44 \%$ in Heyang Village and $27 \%$ to $30 \%$ and Danzhi Village, respectively.

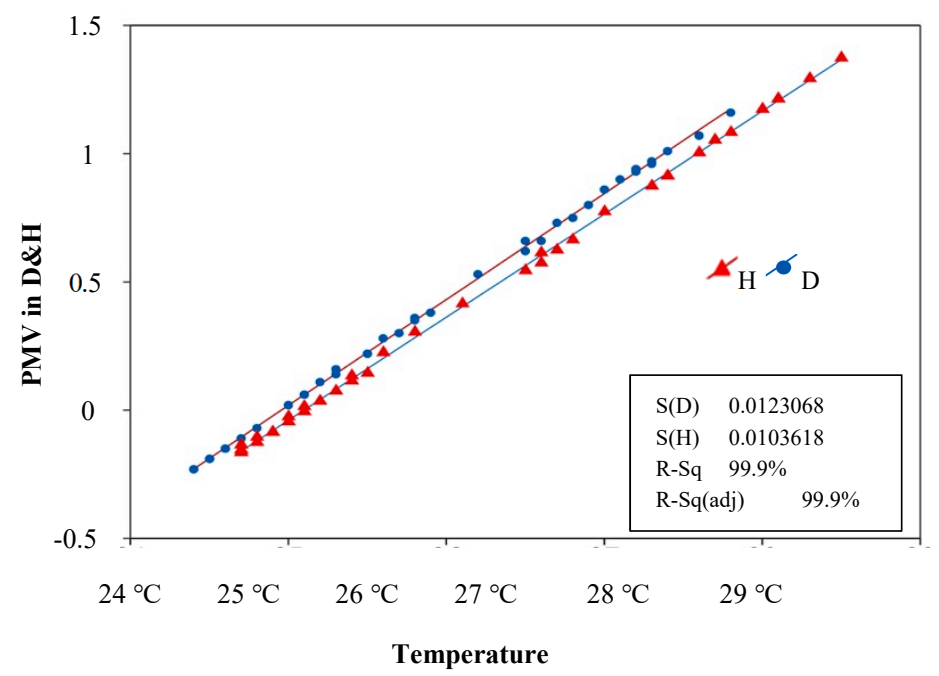

Figure 14. Fitted relationship between temperature and predicted mean vote (PMV) in Heyang $(\mathrm{H})$ and Danzhi (D).

\subsection{Survey Questionnaire and Protocols}

A comfortable indoor environment is essential for a healthy housing environment [44,45]. Occupant comfort and satisfaction are influenced by not only thermal conditions but also lighting, acoustic, and air qualities [46]. To evaluate the quality of the housing environment, the IEQ was assessed in this study using objective physical measurements (e.g., thermal, noise levels, and illuminance) and subjective occupant surveys (satisfaction level). Fifty-three (53) occupants from Heyang and 50 occupants from Danzhi were included in the survey. The sensation scales used in the questionnaire are provided in Table 5, with their numerical equivalents from -3 to +3 . The results of the survey are provided for each aspect in Table 5 in the interval plots in Figure 15. The instrument setup used to capture the 
environmental data was placed on a table close to the subject completing the questionnaire at the height of $1.1 \mathrm{~m}$ as per the ASHRAE 55 Class-II protocols. Occupant responses were then recorded according to the previously defined scales using a value between -3 and +3 . The overall acceptability of the prevailing indoor environment was also noted in binary terms, with 0 indicating "Acceptable" and 1 indicating "Unacceptable" [20].

Table 5. Questionnaire scales used to measure sensations and preferences for indoor parameters.

\begin{tabular}{|c|c|c|c|c|c|c|c|}
\hline $\begin{array}{l}\text { Scale } \\
\text { Value }\end{array}$ & $\begin{array}{l}\text { Thermal } \\
\text { Sensation }\end{array}$ & $\begin{array}{l}\text { Humidity } \\
\text { Sensation }\end{array}$ & $\begin{array}{c}\text { Air } \\
\text { Movement } \\
\text { Sensation }\end{array}$ & $\begin{array}{l}\text { Lighting } \\
\text { Sensation }\end{array}$ & $\begin{array}{l}\text { Acoustic } \\
\text { Sensation }\end{array}$ & $\begin{array}{l}\text { Indoor } \\
\text { Overall } \\
\text { Comfort }\end{array}$ & $\begin{array}{l}\text { Outdoor } \\
\text { Overall } \\
\text { Comfort }\end{array}$ \\
\hline-3 & Cold & Very dry & Very still & Very dark & Very noisy & - & $\begin{array}{c}\text { Very } \\
\text { uncomfortable }\end{array}$ \\
\hline-2 & Cool & $\begin{array}{c}\text { Moderately } \\
\text { dry }\end{array}$ & $\begin{array}{c}\text { Moderately } \\
\text { still }\end{array}$ & $\begin{array}{c}\text { Moderately } \\
\text { dark }\end{array}$ & $\begin{array}{c}\text { Moderately } \\
\text { noisy }\end{array}$ & - & $\begin{array}{c}\text { Moderately } \\
\text { uncomfortable }\end{array}$ \\
\hline-1 & Slight cool & Slightly dry & Slightly still & $\begin{array}{l}\text { Slightly } \\
\text { dark }\end{array}$ & $\begin{array}{c}\text { Slightly } \\
\text { noisy }\end{array}$ & - & $\begin{array}{c}\text { Slightly } \\
\text { uncomfortable }\end{array}$ \\
\hline 0 & Neutral & Neutral & Neutral & Neutral & Neutral & Acceptable & Neutral \\
\hline 1 & $\begin{array}{l}\text { Slight } \\
\text { warm }\end{array}$ & $\begin{array}{l}\text { Slightly } \\
\text { humid }\end{array}$ & $\begin{array}{c}\text { Slight } \\
\text { movement }\end{array}$ & $\begin{array}{c}\text { Slightly } \\
\text { bright }\end{array}$ & $\begin{array}{c}\text { Slightly } \\
\text { quiet }\end{array}$ & Unacceptable & $\begin{array}{c}\text { Slightly } \\
\text { comfortable }\end{array}$ \\
\hline 2 & Warm & $\begin{array}{l}\text { Moderately } \\
\text { humid }\end{array}$ & $\begin{array}{l}\text { Moderate } \\
\text { movement }\end{array}$ & $\begin{array}{c}\text { Moderately } \\
\text { bright }\end{array}$ & $\begin{array}{c}\text { Moderately } \\
\text { quiet }\end{array}$ & - & $\begin{array}{l}\text { Moderately } \\
\text { comfortable }\end{array}$ \\
\hline 3 & Hot & Very humid & $\begin{array}{c}\text { Much } \\
\text { movement }\end{array}$ & Very bright & Very quiet & - & $\begin{array}{c}\text { Very } \\
\text { comfortable }\end{array}$ \\
\hline
\end{tabular}

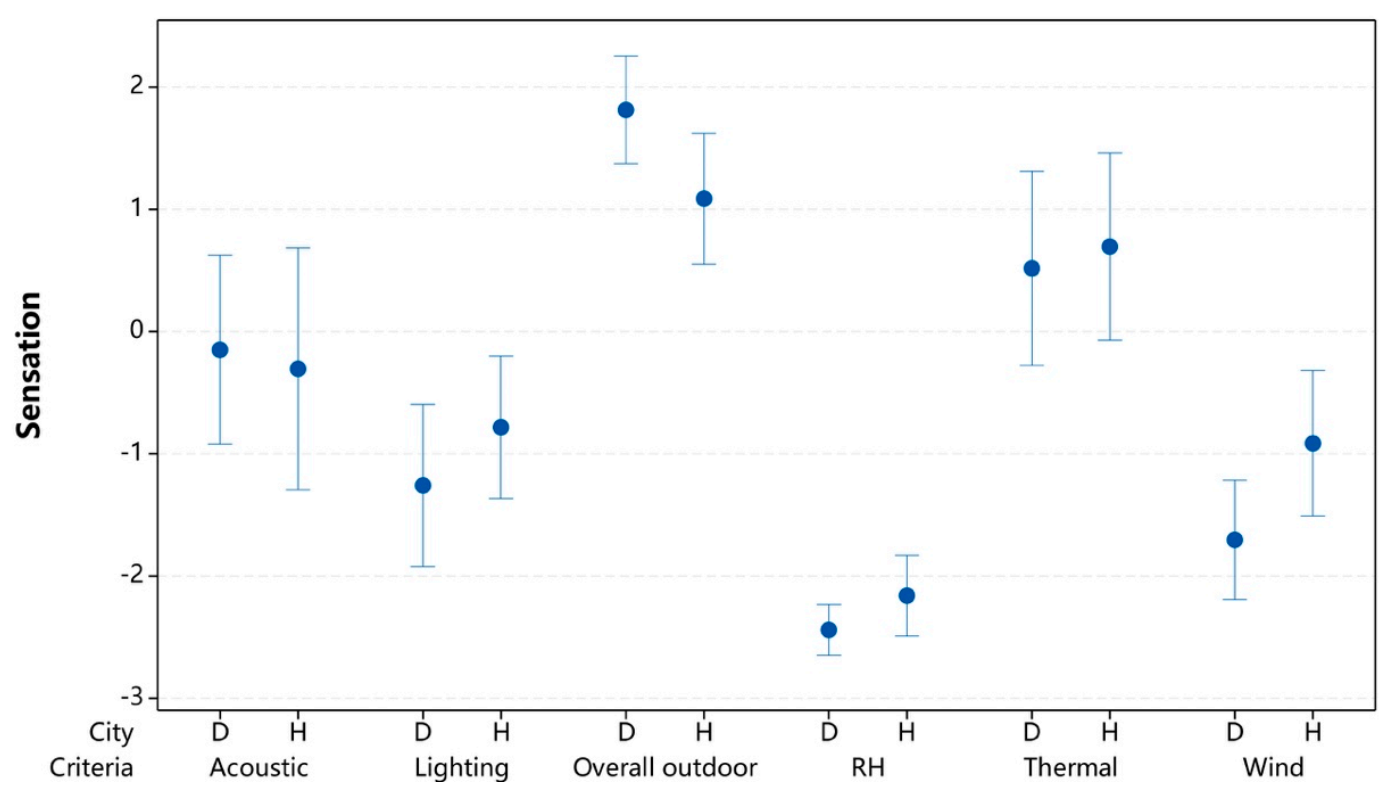

Figure 15. Interval plot of indoor sensations from questionnaire responses.

\subsubsection{Thermal Survey Results}

(1) Thermal scales: Transverse type surveying following ASHRAE 55 Class-II protocols [20] was used in this study. Both "Point-in-time" and "Satisfaction Surveys" were collected. Thermal satisfaction was measured using a seven-point scale bounded by "very satisfied" and "very dissatisfied." Diagnostic questions were asked to identify the causes of dissatisfaction. Thermal acceptability was measured using a seven-point scale bounded by "very unacceptable" and "very acceptable". The thermal sensation was measured using the ASHRAE seven-point thermal sensation scale subdivided into cold, cool, slightly cool, neutral, slightly warm, warm, and hot, as defined in Table 5. 
(2) Subjective thermal acceptability: This study investigated the thermal comfort environment that is acceptable to $80 \%$ of the residents as specified in the ASHRAE and ISO 7730 standards; that is, an acceptable temperature range in which the PPD is less than or equal to $20 \%$. The survey results revealed that the upper limit of acceptable temperature for $80 \%$ of the residents was $31{ }^{\circ} \mathrm{C}$ during the plum rain season. Specifically, the interval plots in Figure 15 show that the residents of the two subject villages were slightly dissatisfied with the air movement sensation during the plum rain season, and this dissatisfaction was worse in Danzhi Village. Thermal pressure ventilation and wind pressure ventilation did not form due to the low wind speed, lack of solar radiation, and the small temperature difference between indoors and outdoors. Residents of both villages were also very dissatisfied with the indoor humidity, with $71 \%$ of the residents in Danzhi Village and $53 \%$ of the residents in Heyang Village, indicating that it was unacceptable. This low satisfaction was due to the continuous rainfall during the plum rain season that resulted in high indoor and outdoor humidities averaging over $90 \%$. The low wind speed and extended period of high humidity also reduced the humidity tolerance of the residents. Furthermore, Danzhi Village is located in a dense forest, which minimized vapor diffusion and resulted in even higher humidity than in Heyang Village, which is located in an open plain. Nevertheless, residents of both villages were slightly satisfied with the overall indoor thermal comfort because the temperatures during the plum rain season were mostly within the comfort zone; only 33.33\% of the residents in Danzhi Village and 26.19\% of the residents in Heyang Village indicated that the temperature was unacceptable. Note that the outdoor comfort satisfaction was also high at $92.59 \%$ and $86.96 \%$ for the residents of Danzhi Village and Heyang Village, respectively.

The results of the thermal satisfaction survey indicated that the temperature was only uncomfortably high in the afternoon during the plum rain season, but the residents were very dissatisfied with the humidity and the air movement sensation. At the same time, the results demonstrated that the residents were more concerned with the temperature in the overall evaluation of thermal comfort and expressed a lower expectation for humidity. As a result, the residents were slightly satisfied with the overall thermal comfort.

\subsubsection{Lighting Survey Results}

Compared to thermal comfort, lighting is often overlooked when evaluating the design and construction of ancient dwellings. The China Standard for the daylighting design of buildings (GB 50033-2013) [43] considers the lighting coefficient and the illuminance of indoor natural light as evaluation indices for lighting design: the lighting coefficient of the side lighting of bedrooms and living rooms of residential buildings should be no less than $2 \%$, and the illuminance of indoor natural light should be no less than 300 lx. The measurement results, shown in Table 4, indicate that the indoor illuminance in the two villages was lower than the GB 50033-2013 standard, even with ample sunshine in the summer. This was because the subject dwellings have only small window openings; although this is conducive to mitigating indoor solar radiation, it is detrimental to lighting. The indoor lighting environment in the two villages was far below the standard for writing and reading, and thus the lighting design needs to be enhanced. As indicated by the low interval in Figure 15, the current status of the lighting environment was deemed unacceptable by $65.22 \%$ and $70.37 \%$ of the residents in Heyang Village and Danzhi Village, respectively.

\subsubsection{Acoustic Survey Results}

The indoor acoustic environment is typically evaluated from the perspective of the indoor noise level, the sound reduction index of the building or structural components, and the sound insulation of floor impacts [41]. The measurements, shown in Table 4, indicate that the noise level during the plum rain season was significantly higher than the ASHRAE standard. This was likely a result of the poor sound insulation of the wood used as the interior material for the dwellings as well as natural factors, such as the continuous rainfall. As shown in Figure 15, the residents of the two villages expressed slight dissatisfaction with the acoustic environment; it was considered unacceptable by $52.17 \%$ of the 
residents in Heyang Village. Additionally, note that the acoustic environment satisfaction in Danzhi Village was higher during the daytime than during the nighttime: the relatively remote location of Danzhi Village limited the impact of traffic noise during the daytime, whereas the development of tourism in Heyang Village resulted in higher noise levels during the daytime. The natural noise generated by the U-shaped river dam in Danzhi Village was the primary source of noise at night.

\section{Discussion}

The results of this study have several limitations that remain to be addressed in future research. First, the respondents to the questionnaire survey were mainly women, the seniors, and children, as most of the young and middle-aged men migrate to urban areas for work, a typical phenomenon in mountainous rural areas. In other words, the sample employed in this study does not adequately represent the age structure of the population as young and middle-aged men are underrepresented, and women and the seniors are overrepresented. Notably, the seniors typically have a lower expectation for thermal comfort. As a result, their high thermal comfort ratings likely compromise the significance of the results of this research. However, because the seniors have a relatively low metabolic capacity and immunity, a thermoregulation model could be established specifically for the seniors as a separate population group using the data collected in the present study.

The two villages investigated in this study have an altitude difference of only $100 \mathrm{~m}$. In future research, traditional dwellings in the same geographical region but with larger altitude differences will be considered to better reveal the effect of microclimate on climate responsive design strategies and thermal comfort. Additionally, the sample size per altitude group in this study is not large enough to conduct a reliable statistical analysis: the overall sample size (103) is not small but consists of subjects in several different altitude groups. In future research, a larger data sample will be collected, as larger sample generally yields more accurate and convincing statistical analysis results.

Note that the effect of the area and location of building spaces occupied by the respondents on the results of the questionnaire survey was not considered in this study. Although the measurement data were obtained from typical residents in typical dwellings, the location and area of the building spaces they occupied were not considered. Controlling the effect of the spatial properties and location of the building spaces occupied by different individual residents would likely contribute to more accurate and applicable research results.

In their current form, the results of this study can serve as a supplement to existing local and provincial IEQ standards and design guidelines. They also have practical implications in the design of residential buildings that are more adaptive to different local climates. The future study directions discussed in this section will contribute to the establishment of robust post-occupancy evaluation-based design guidelines. Note that although this study identified the climate responsive design strategies of dwellings in specifically stereoscopic climates and geographic environments, there is potential for the synchronous optimization of enclosure structures to achieve sustainable development of buildings in other hot and humid climates. Therefore, further studies will include comparative analyses of the climate-responsive strategies and indoor thermal environments of different types of buildings in different stereoscopic climates. Future research will also investigate the optimization of climate-responsive strategies through computer simulations while considering modern lifestyles, natural environments, and the culture of the subject region, as well as the translation of these strategies into the modern context in the subject region.

\section{Conclusions}

Based on the "microclimate" geographical scale, this study investigated the indoor physical environment and associated resident comfort for dwellings in the complex stereoscopic climate of Danzhi and Heyang villages in southern Zhejiang Province in order to research their climate response strategies. This paper accordingly analyzed the effects of the climate adaptive architecture of residential buildings in terms of the indoor thermal, lighting, and acoustic environments using "right here and 
right now" comfort surveys and measurements. Outdoor climate parameters were obtained from the 20-year average data of adjacent weather stations. The conclusions of this study are as follows:

(1) Ancient dwellings in southwestern Zhejiang Province have achieved some success with their specific climate responsive strategies against wind and solar radiation; the microclimates in the courtyard and in the building rooms have been found to be stable.

(2) Due to the long warm season in southwestern Zhejiang Province, residential buildings are designed for hot weather and focus on the thermal comfort environment. The average wind speed is low, which is not conducive to building wind pressure ventilation. Therefore, heat insulation and organization of thermal pressure ventilation to cool the dwellings form the basis of climate coping strategies. Thermal pressure ventilation is created by enclosing the residence in an exterior wall to generate a drafting effect, installing overhanging eaves to provide shading, provisions of a cooling avenue, and allowing airflow through the roof tile gaps. In the plum rain season, however, the ventilation provided by these measures remains inadequate.

(3) The reasonable selection of settlement site and layout style is the first step in design, considering both the natural environment and resident comfort. Both villages are built close to a river to ensure sufficient sunshine and temperature adjustment. The geographical environment has a significant influence on the distribution pattern of the subject settlements: the dwellings in Danzhi Village are shorter with smaller building shape coefficients that help to resist mountain storms.

(4) A dwelling layout with an inner courtyard offers a basic strategy to cope with the varying external climate by creating an internal microclimate. Still, no significant difference in the average outdoor and indoor temperature and humidity has been observed during the plum rain season. The inner courtyard structure is unfavorable to the formation of wind pressure ventilation that creates the sensation of air movement for occupants. Limited by the mountainous terrain, the courtyards of traditional homes in Danzhi Village are smaller. The results showed that the thermal comfort of dwellings with a double inner courtyard in Heyang Village is better than that of dwellings with a single inner courtyard in Danzhi Village. The area and height of the inner courtyard are the key factors affecting ventilation.

(5) The courtyard/living room/patio space composes the ventilation system, representing one of the most effective strategies of adapting to the climate while providing cooling. As the main indoor activity area during the day, the outside wall of the living room is open to the adjacent side of the inner courtyard, and the living room ceiling reaches up to the roof, thus allowing rising heat to form a ventilation path carrying the hot and humid air outside. Furthermore, two layers of hanging eaves mitigate strong solar radiation in the courtyard and provide insulation, shade, and rain protection.

(6) The building envelope material is a critical component of climate-responsive design optimization. The outside face of the dwelling enclosure uses building materials with high thermal inertia and thickness, such as rammed earth walls or stones, and include small windows to resist changes in the environment. The inside face of the dwelling enclosure uses building materials with low thermal inertia, such as wood, with large windows for heat dissipation and ventilation, helping to take away moisture. This serves to make the indoor thermal environment consistent with that in the courtyard. The indoor environment has been found to be more humid in Danzhi dwellings, which have elevated stone foundations used to isolate moisture from the ground.

(7) In the plum rain season, the high humidity both indoors and outdoors affects the insulation performance of the dwelling envelope. Moreover, residents are accustomed to having the windows open all day and night. The most important factors influencing indoor thermal comfort are that the sun does not create evaporative heat dissipation during days of continuous rain and that the wind tends to be calm. Residents are expected to feel stuffy, humid, and hot, low wind satisfaction. Indeed, in the plum rain season, the humidity is above $94 \%$ all day. Mechanical dehumidification is necessary to achieve comfort requirements in the two subject villages. 
(8) Based on the results of the questionnaire survey and IEQ model, the upper limit of acceptable temperature for $80 \%$ of the residents in summer is $31^{\circ} \mathrm{C}$, which is higher than the comfort range of $22{ }^{\circ} \mathrm{C}$ to $28^{\circ} \mathrm{C}$ dictated by ASHRAE 55. The comfort zone of the residents is also wider than that given in the ASHRAE 55 standard. This is evidence of the adaptation of the residents to the indoor environment through their long-term occupancy in the region, resulting in higher individual thermal tolerance and a lower expectation of indoor thermal comfort. According to the measurements, the indoor temperature of the two villages is consistently less than $31^{\circ} \mathrm{C}$, both day and night, so the indoor temperature is within the acceptable temperature zone in southern Zhejiang during the plum rain season.

(9) Due to the focus on the design of the thermal environment of the dwellings, the quality and comfort of the lighting and acoustic indoor environments were not achieved. To improve the indoor lighting environment, the window-to-wall ratio of the dwellings should be increased, and the depth of the eaves should be adjusted according to the incident angle of the sun. To improve the indoor acoustic environment, the sound insulation effect of wood of the interior structure is inadequate. It is, therefore, necessary to strengthen the sound insulation performance of the building or its structural components to reduce the impact of noise on the indoor environment.

In this paper, Jinyun, Zhejiang, has a unique stereoscopic climate. The two types of dwellings were compared, and the analysis results demonstrated that both have methods of responding to the hot and humid climate during the plum rain season. For example, they use different sites, courtyard space ratios, shape coefficients, and structural details, but the same shading, ventilation, full structural system, and heat dissipation to ensure a local and constant microclimate in the courtyard. All these methods are design strategies that residents use to adapt to microclimatic characteristics. These strategies have combined information collected over the years and strongly confirmed the climate responsiveness of traditional dwellings in pursuit of a comfortable environment. However, owing to the limitations of the natural operation of buildings, residents still rely on mechanical dehumidification to cope with highly humid environments. In addition, design strategies need to be altered to alleviate the indoor lighting and acoustic discomfort caused by the construction strategy that prioritizes thermal environments.

Author Contributions: Conceptualization, R.Z., J.-H.C. and L.C.; methodology, R.Z. and J.-H.C.; formal analysis, R.Z., J.-H.C.; software, Y.Z. and L.C.; data curation, L.C.; investigation, R.Z., J.-H.C. and L.C.; writing-original draft preparation, R.Z., J.-H.C. and H.J.; resources, L.C. and R.Z.; visualization, L.C. and Y.Z.; validation, L.C. and Y.Z.; writing - review and editing, J.-H.C. and H.J.; supervision, R.Z. and J.-H.C. project administration, R.Z. and L.C. All authors have read and agreed to the published version of the manuscript.

Funding: This project was made possible with support from the National Natural Science Fund of China (No. 51978623).

Acknowledgments: The authors appreciate Zhu, W. at Zhejiang University, for the advice for this study. Further, the authors want to express their gratitude to Yucheng, L., Rui, H., and Xuecheng, X. of ZUST students who participated in the experiments.

Conflicts of Interest: The authors declare no conflict of interest.

\section{References}

1. Huang, W. Architectural form and climate design. Archit. J. 1993, 3, 10-14.

2. Bhai, Z.J.; Previtali, J.M. Ancient vernacular architecture: Characteristics categorization and energy performance evaluation. Energy Build. 2010, 42, 357-365.

3. Okay, D. Design with the climate in housing environments: An analysis in Northern Cyprus. Build. Environ. 2002, 37, 1003-1012. [CrossRef]

4. Junge, L.; Liu, Y.; Jiaping, L. Adaptive thermal comfort model for hot summer and cold winter zone. Heat. Vent. Air Cond. 2008, 38, 20-25.

5. Ke, H.; Jun, J.; Qiuting, W.; Chengkang, W. Argument about healthy architecture in Japan. Archit. Cult. 2014, $8,85-86$. 
6. Yun, Q.; Yiran, Y. A survey of the morphology research progress of settlement vernacular in foreign countries. In Proceedings of the First International Conference on Architectural and Cultural Heritage in China's Ethnic Inhabited Areas; Digital Publishing Press: Beijing, China, 2010; pp. 76-78.

7. Yehao, S.; Jialiang, W.; Ning, Z. Pondering over the passive design strategy or native green buildings of China. Archit. J. 2013, 7, 94-99.

8. Xue, W.; Liu, Y.; Jiaping, L.; Hui, C.; Yuan, C. Indoor thermal environment and energy consumption characteristics of folk houses in mountainous region in Southern Shaanxi in summer. J. Xi'an Univ. Archit. Technol. 2018, 50, 563-568.

9. Liu, Y.; Qian, Y.; Haiyan, Y.; Jiaping, L. Field study on thermal comfort of rural houses in winter in a the Guanzhong region, Shaanxi Province. J. Xi'an Univ. Archit. Technol. 2011, 43, 551-556.

10. Fang, W. The traditional dwellings evolution mechanism in Nujiang Basin Multi-ethnic Mixed Areas. New Archit. 2018, 5, 129-133.

11. Jimin, Z. Study on evolution of stilt folk building in north area of Gulin city. Archit. Technol. 2019, 50, 382-384.

12. Sasa, D. Creation of Regional Architecture Based on the Formal Language of Traditional Dwellings in the Central of Zhejiang. Ph.D. Thesis, Zhejiang SCI-TECH University, Hangzhou, China, 2013.

13. Xinke, Z. Analyzing the beauty of form in the folk houses culture in the north of Zhejiang. Pop. Lit. 2013, $13,57-58$.

14. Dan, H.; Songhua, D. Study on regionality and construction context of rocky folk house in central part of Guizhou. Archit. J. 2013, 5, 105-110.

15. Yizhi, Z. A pedigree study on the wooden bracket of vernacular architectures in southeast coast of China. Archit. J. 2016, S1, 103-107.

16. Yan, M. Study on Climate Adaptability of Human Beings to Thermal Comfort in China. Ph.D. Thesis, Xi'an University of Architecture and Technology, Xi'an, China, 2007.

17. Tove, M. Environmental rating methods: Selecting indoor environmental quality (IEQ) aspects and indicators. Build. Res. Inf. 2008, 36, 466-485.

18. Linsheng, T.; Zhiyong, W.; Sheng, L.; Jize, S. Research on the residential passive-house design strategies based on the improvement ofindoor thermal environment in North Hunan. J. Hunan Univ. Technol. 2016, $30,78-84$.

19. Zhao, Q.; Liu, P.; Zhu, Y. Rural residence passive design strategies in Southern Shaanxi based on improving thermal comfort. J. Xi'an Univ. Technol. 2014, 30, 315-319.

20. ASHRAE Standard 55. Thermal Environmental Conditions for Human Occupancy; American Society of Heating, Refrigerating, and Air-conditioning, Inc.: Atlanta, GA, USA, 2010.

21. Humphreys, M.A. Outdoor temperatures and comfort indoor. Build. Res. Pract. 1978, 2, 92-105. [CrossRef]

22. Guide to Meteorological Instruments and Methods of Observation, 6th ed.; WMO-No. 8; World Meteorological Organization: Geneva, Switzerland, 1996.

23. Xiangde, X.; Xu, T. Causes of Urbanization Environmental Mete Rology; Meteorological Press: Beijing, China, 2002; Volume 1.

24. Britannica. Available online: https://www.britannica.com/science/mesoclimate (accessed on 11 February 2020).

25. The Free Dictionary. Available online: https:/encyclopedia2.thefreedictionary.com/Local+Climate (accessed on 11 February 2020).

26. Sapozhnikova, S.A. Mikroklimat i Mestnyi Klimat; The Great Soviet Encyclopedia: Leningrad, Russia, 1950.

27. Haomin, W.; Yanmin, J.; Yuhua, Q. Analysis of mountain stereo climate resources in baiyun mountain forest park, Lishui. J. Zhejiang Meteorol. 2018, 39, 11-16.

28. Baidubaike. Available online: https://baike.baidu.com/item/\%E7\%AB $\% 8$ B $\%$ E4 $\% B D \% 93 \% E 6 \% B 0 \% 94 \% E 5 \%$ 80\%99/3933126?fr=aladdin (accessed on 11 February 2020).

29. Royal Meteorological Society. Available online: https:/encyclopedia2.thefreedictionary.com/Micro+climate (accessed on 11 February 2020).

30. Peng, C. The entrance and exit research of the folk building, such as the district of Jinyun Zhejiang province. Art Des. (Theory) 2010, 2, 122-124.

31. Rong, L. The Correlation Research of Residential Building Indoor Physical Environment Performance and Energy Consumption in Hot Summer and Cold Winter Area. Ph.D. Thesis, Chongqing University, Chongqing, China, 2017. 
32. DB 33-T 912-2014. Construction Regulation for Beautiful Village; Zhejiang Bureau of Quality and Technical Supervision: Hangzhou, China, 2014; pp. 4-6.

33. T/ASC 02-2016. Assessment Standard for Healthy Building; The Architectural Society of China: Beijing, China, 2017; pp. 1-6.

34. GBT/50178-93. Standard of Climatic Regionalization for Architecture; Ministry of Construction Development of the People's Republic of China: Beijing, China, 1993; pp. 9-11.

35. Jinyun Government. Available online: http://www.jinyun.gov.cn/2007zjjy/jygl/ (accessed on 2 June 2019).

36. China Webmater. Available online: http://lishi.tianqi.com/jinyun/201909.html (accessed on 2 June 2019).

37. Shimeng, H.; Yehao, S. An analysis of the concepts of climate response under various architectural systems. Archit. J. 2016, 9, 103-104.

38. Wikipedia-Adaptation. Available online: https://en.wikipedia.org/wiki/Adaptation (accessed on 11 February 2020).

39. Choi, J.H.; Lee, K. Investigation of the feasibility of POE methodology for a modern commercial office building. Building and Environment 2018, 143, 591-604. [CrossRef]

40. Olgyay, V. Design with Climate; University Press: Princeton, NJ, USA, 2015.

41. ASHRAE 129. Standard Method of Measuring Air Change Effectiveness; American Society of Heating, Air-Conditioning, and Refrigerating Engineerings, Inc.: Atlanta, GA, USA, 1997.

42. GBT/50785-2012. Evaluation Standard for Thermal Indoor Environment in Civil Buildings; Ministry of Housing and Urban Rural Development of the People's Republic of China: Beijing, China, 2012; pp. 9-21.

43. GB 50033-2013. Standard for Daylighting Design of Building; Ministry of Housing and Urban Rural Development of the People's Republic of China: Beijing, China, 2013.

44. Yu, C.W.F.; Kim, J.T. Building environmental assessment schemes for rating of IAQ in sustainable buildings. Indoor Built Environ. 2011, 20, 5-15. [CrossRef]

45. Lee, T.K.; Cho, A. Residents' adjusting behaviour to enhance indoor environmental comfort in apartments. Indoor Built Environ. 2012, 21, 28-40. [CrossRef]

46. 2013 ASHRAE Handbook-Fundamentals; American Society of Heating, Air-Conditioning, and Refrigerating Engineerings, Inc.: Atlanta, GA, USA, 2013.

(C) 2020 by the authors. Licensee MDPI, Basel, Switzerland. This article is an open access article distributed under the terms and conditions of the Creative Commons Attribution (CC BY) license (http://creativecommons.org/licenses/by/4.0/). 